\title{
PATOLOGIAS DE FUNDAÇÕES/INFRAESTRUTURA: AVALIAÇÃO E PROPOSTA DE PROJETO DE CONTENÇAO PARA HABITAÇÕES DE INTERESSE SOCIAL
}

\author{
LIMA DOS SANTOS, JAQUELINE \\ Graduanda \\ UFPA \\ PA; Brasil \\ Jaqueline_lima19@outlook.com
}

\author{
PEREIRA GOUVEIA, FERNANDA \\ Docente, Dra. \\ UFPA \\ Pará; Brasil \\ gouveia@ufpa.br
}

\author{
CRUZ DA SILVA ARAUJO, JULIENE \\ Graduanda \\ UFPA \\ Pará; Brasil \\ Julliene.silva@hotmail.com
}

\section{RESUMO}

Os empreendimentos de habitação de interesse social geralmente apresentam manifestações patológicas devido a projetos inadequados às especificidades do terreno, erros de execução e negligências técnicas. O projetista deve considerar recomendações sobre estabilidade de taludes (conforme Código de Práticas da Caixa Econômica Federal) quando existirem desníveis no terreno. Tais recomendações foram ignoradas na concepção do empreendimento Cristo Vive; dentre as 604 casas construídas, 137 apresentam patologias, sendo observados desde problemas como erosões até desmoronamentos. O objetivo da pesquisa foi elaborar um projeto de contenção do solo para o empreendimento, prevendo os custos, sendo realizadas visitas in loco para registro das medições dos lotes, elaboração do projeto e orçamento. Como resultado, obteve-se um projeto adequado ao Código de Práticas, com custo de aproximadamente $\mathrm{R} \$ 330.000,00$. Foram analisados desníveis de até 1,5 m e para estes casos, indicou-se execução de taludes com drenagem na sua base.

Palavras-chave: contenção, talude, projeto.

\section{ABSTRACT}

Housing developments of social interest often present pathological manifestations due to projects inappropriate to the specificities of the land, errors of execution and technical negligence. The designer should consider slope stability recommendations (as per Caixa Econômica Federal Code of Practice) when there are gaps in the ground. Such recommendations were ignored in the conception of the Cristo Vive enterprise; Among the 604 houses built, 137 have pathologies, being observed from problems such as erosion to collapse. The objective of the research was to elaborate a project of soil containment for the enterprise, predicting the costs, being carried out on-site visits to register the measurements of the lots, project elaboration and budget. As a result, we obtained a project appropriate to the Code of Practice, with a cost of approximately $\mathrm{R} \$ 330,000.00$. Slopes of up to $1.5 \mathrm{~m}$ were analyzed and for these cases, execution of slopes with drainage at its base was indicated.

Keywords: contention, slope, project.

\section{INTRODUÇÃO}

Ocorrendo desde 2009, o Programa Minha Casa Minha Vida (PMCMV) tem sido responsável pelo acesso à casa própria de milhões de famílias brasileiras de baixa renda, que recebem salários de até R $\$ 1600,00$. Sabe-se que o processo adequado desde a fase de projeto, passando pela fase de construção - sobre a qual Gomes et al (2017) coloca que é fundamental a checagem da execução dos serviços com o objetivo de promover qualidade às edificações - até o acompanhamento de manutenção na fase de pós obra, em que Soares et al (2014) afirma a respeito da importância da manutenção preventiva já que esta é capaz de reduzir os custos que ocorreriam em uma manutenção corretiva das edificações, permitem que se chegue, como resultado final, à moradias de qualidade para os usuários. 
Durante os últimos anos, entretanto, as residências do PMCMV têm sido alvo de vários estudos e pesquisas acerca das manifestações patológicas notadas nestes empreendimentos e sua precoce aparição. Neste contexto, Freitas et al (2017) afirma que as principais manifestações encontradas são "rachaduras, trincas, fissuras, corrosão da armadura e infiltrações."

Gomes et al (2017) pontua ainda, que "edificações voltadas para a população de baixa renda tem exigido um alto número de manutenção corretiva devido a falhas construtivas encontradas frequentemente"; falhas estas, presentes desde a fase de projeto até a manutenção das obras finalizadas.

Um erro comumente notado durante a elaboração destes projetos de engenharia voltados ao interesse social - como é o caso das obras executadas pelo (PMCMV) que, exatamente pelo interesse social envolvido, buscam privilegiar o baixo custo no processo executivo - é a não consideração das especificidades do local a ser construído o empreendimento, fator potencial para levar a problemas e disfunções notadas durante a execução e que tendem a perdurar durante a vida útil da estrutura, caso não sejam tomadas as medidas de correção.

No caso do Residencial Cristo Vive - Localizado na Cidade de Tucurúi/PA, não foram considerados os significativos desníveis presentes na topografia do local; com as edificações entregues aos moradores, passaram a ser notórias situações de erosões e desmoronamentos do terreno devido aos desníveis, pondo em risco a segurança da edificação, já que as fundações foram executadas sobre solo com instabilidade.

A respeito das fundações, de acordo com Alonso (2011), para a execução de uma fundação adequada que garanta a segurança da edificação, é necessária a realização de um estudo aprofundado do local onde será executada a estrutura, a verificação do tipo de solo, da topografia do terreno, dados geológicos e geotécnicos, a fim de determinar e dimensionar a fundação que suporte às solicitações de cargas. Na ausência desse estudo, pode haver o surgimento de patologias.

Considerando as fundações superficiais, como é o caso da fundação utilizada nas residências do Residencial Cristo Vive, Milititsky, Consoli e Schnaid (2005) apresentam situações que podem ocorrer por conta da ausência do estudo do solo adequado ao tipo de fundação, sendo estas: fundações sobre solos compressíveis, fundações apoiadas em solo de comportamento muito diferente, fundações sobre aterros e tensões de contato excessivas, incompatíveis com as características reais do solo. Situações estas que podem ocasionar recalques diferenciais, deformações ou até ruptura e grandes deslocamentos da fundação.

Para o empreendimento deste estudo de caso, a fundação executada foi a superficial do tipo radier que é adequada ao tipo de estrutura, já que é de pequeno porte tendo as solicitações de cargas não elevadas. O problema, foi apenas a falta de contenção do solo nas proximidades da fundação, ocorrendo desmoronamentos do mesmo e atingindo boa parte do solo abaixo da fundação, sendo válido ressaltar que não havia projeto de contenção do solo previsto para o terreno.

Dentre as soluções para esse tipo de problema, Luiz (2014) cita os muros, solos grampeados e as cortinas ancoradas. Conforme o autor, os muros são divididos em dois tipos: os de peso ou gravidade (construídos de alvenaria de pedras, concreto ciclópico, gabiões, solo-cimento ou solo reforçado) e os de flexão (construídos de concreto armado com ou sem contrafortes). De acordo com Luiz (2014) apud Elias, Christopher e Berg (2001), o muro em solo reforçado é uma solução de fácil execução, baixo custo, rápida execução e não necessita de mão de obra especializada. A face do solo é protegida com vegetação.

Conforme Alves et al (2017), quando ocorrem manifestações patológicas, ocorre também a necessidade de uma futura medida de correção que se configura onerosa e causadora de prejuízos tanto à construtora quanto aos moradores.

Dentre as 604 casas construídas neste conjunto habitacional $(\mathrm{CH}), 137$ apresentam patologias, sendo observados desde problemas mais simples como erosões até desmoronamentos. Portanto, para essas situações de desníveis é necessária a execução de soluções de contenção de forma a garantir a estabilidade do solo e a segurança da edificação.

Neste sentido, Luiz (2014) afirma que:

As estruturas de contenção são obras de engenharia civil necessárias quando o estado de equilíbrio natural de um maciço de solo ou de rocha é alterado por solicitações que podem ocasionar deformações excessivas e até mesmo o colapso. A estrutura deverá então suportar as pressões laterais (empuxo) do material a ser contido de forma a garantir segurança ao talude. 
Neste contexto, segundo Gerscovich (2016), para solucionar esta problemática, dependendo da situação, podem-se adotar taludes com cobertura vegetal. Considerando essa alternativa das contenções por meio de taludes, Carneiro e Pinotti (2013) trazem sua definição como sendo superfícies inclinadas cujo substrato é de natureza terrosa, rochosa ou mista; além disto, podem ter sua origem por ações naturais ou por interferência do homem, como por exemplo, por meio de aterros ou cortes.

Quanto à influência da vegetação na estabilidade dos taludes, Coppin e Richards (1990) afirmam que "mecanicamente, a vegetação aumenta a resistência do solo, e consequentemente contribui para a resistência do solo" (apud Michel, 2013).

\section{JUSTIFICATIVA}

A Caixa Econômica Federal elaborou um código de práticas construtivas que é repassado às construtoras responsáveis por suas obras de produções habitacionais com o objetivo de promover qualidade ao produto final que é entregue aos moradores. Este documento de referência, de 2016, afirma a respeito da necessidade de estruturas de contenção para desníveis superiores a $1 \mathrm{~m}$. No caso de desníveis de até $1,5 \mathrm{~m}$, são previstas soluções por meio de taludes com proteção vegetal em toda a sua extensão e dispositivo de drenagem no pé do talude.

No caso da obra em questão, estes parâmetros preconizados no código de práticas não foram seguidos e, por conta disto, o solo instável passou a ceder pelos carregamentos impostos e foram notadas as manifestações patológicas. Dada a ocorrência destes problemas surgiu a necessidade de solucioná-los através da elaboração de projeto coerentes à realidade local e ao código de práticas da Caixa Econômica Federal supracitado.

\section{OBJETIVOS}

Este estudo de caso tem a finalidade de propor a solução para a problemática apresentada através da elaboração de projeto de contenção do solo a fim de proporcionar rigidez e segurança às edificações e aos seus ocupantes durante a vida útil das edificações, desde que executadas as medidas de manutenção pré-estabelecidas.

\section{METODOLOGIA}

A fim de atingir os objetivos, o presente estudo de caso seguiu o fluxograma disposto na Figura 1:

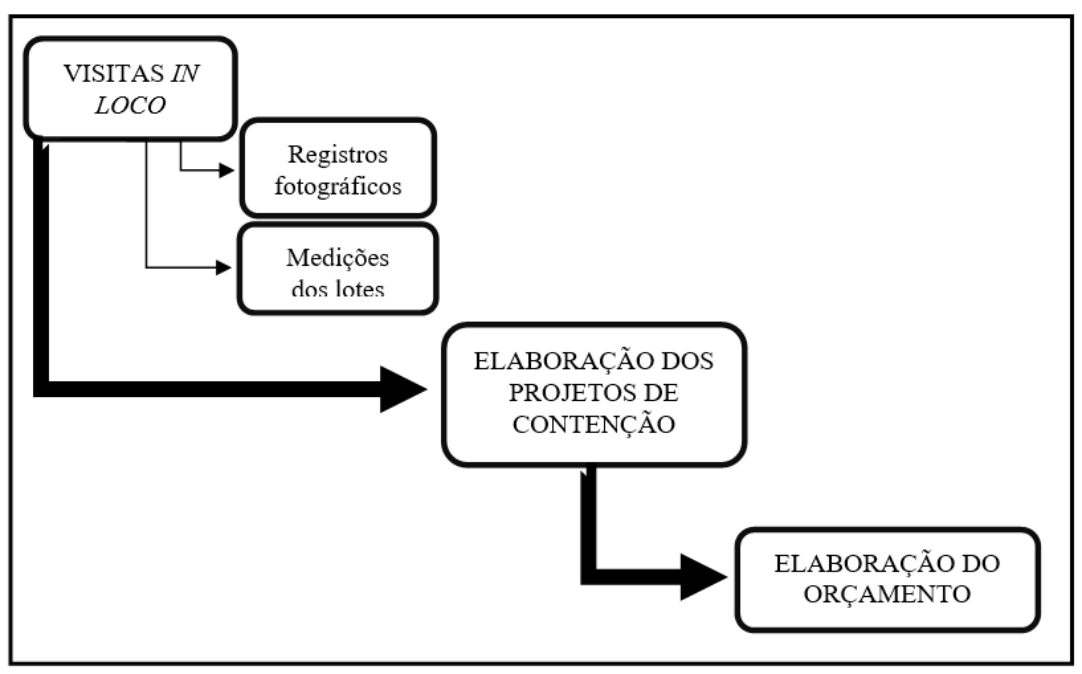

Figura 1: Metodologia adotada. Fonte: dos autores.

As visitas in loco e medições dos lotes foram realizadas entre os meses de junho e julho de 2019, utilizando câmera fotográfica e trena; além de consulta a projeto arquitetônico; A elaboração do projeto de contenção foi realizada através do software AutoCAD (2016). O orçamento foi realizado com base na planilha SINAPI da Caixa Econômica Federal, de acordo com os dados disponíveis em novembro de 2019, para o estado do Pará com o auxílio do software Excel (2013). 


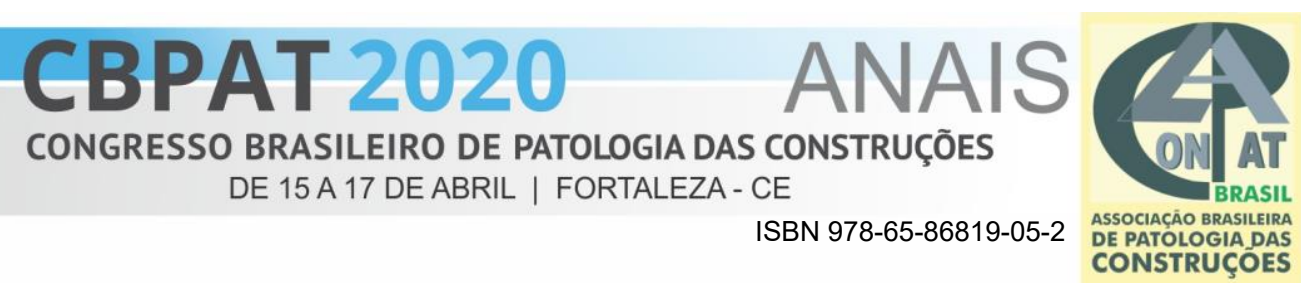

\section{RESULTADOS E DISCUSSÕES}

\subsection{Levantamento de dados - visitas in loco}

A Figura 2 apresenta a planta baixa das edificações que fazem parte do condomínio Cristo Vive localizadas em Tucuruí/PA, possuindo $40,03 \mathrm{~m}^{2}$ de área construída cada.

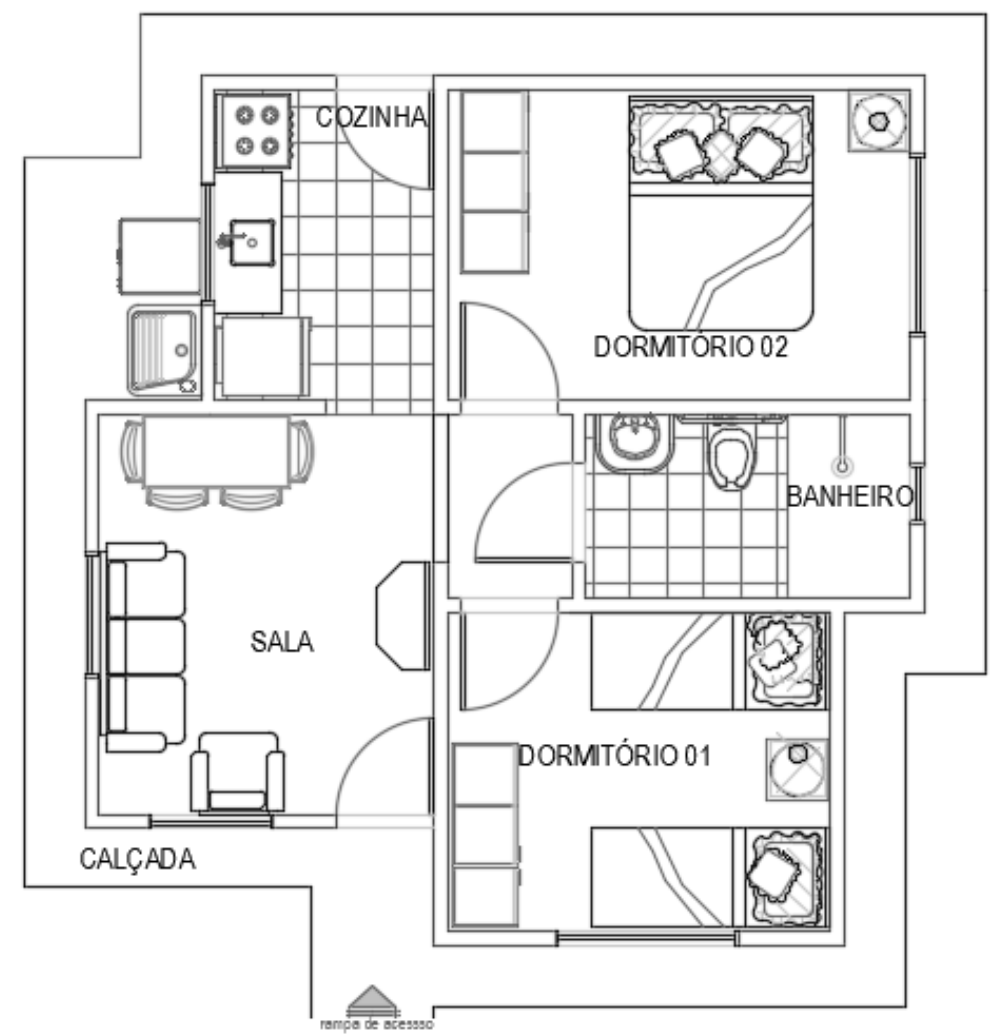

Figura 2: Planta baixa das edificações. Cotas em centímetros. Fonte: dos autores.

As Figuras 3 e 4 apresentam as condições encontradas nas residências coma ocorrência dos problemas de instabilidade do solo no $\mathrm{CH}$.

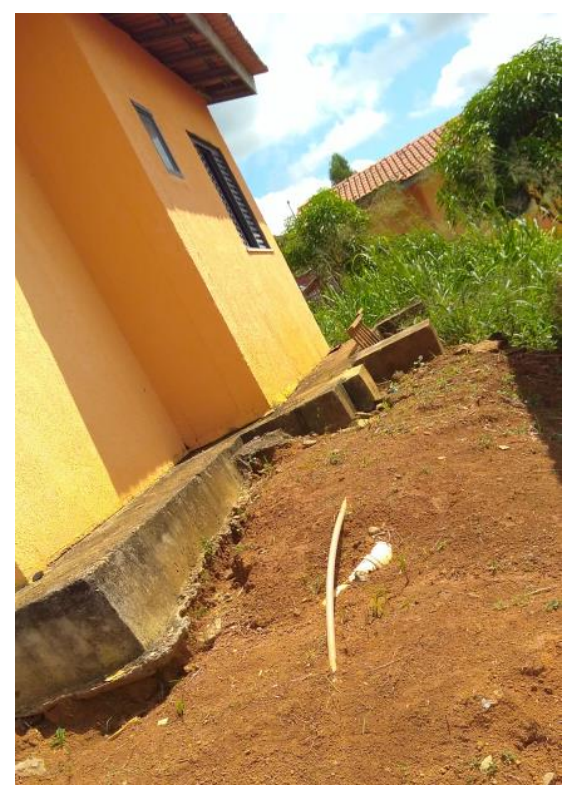

Figura 3: Solo cedendo - vista de uma residência. Fonte: dos autores. 


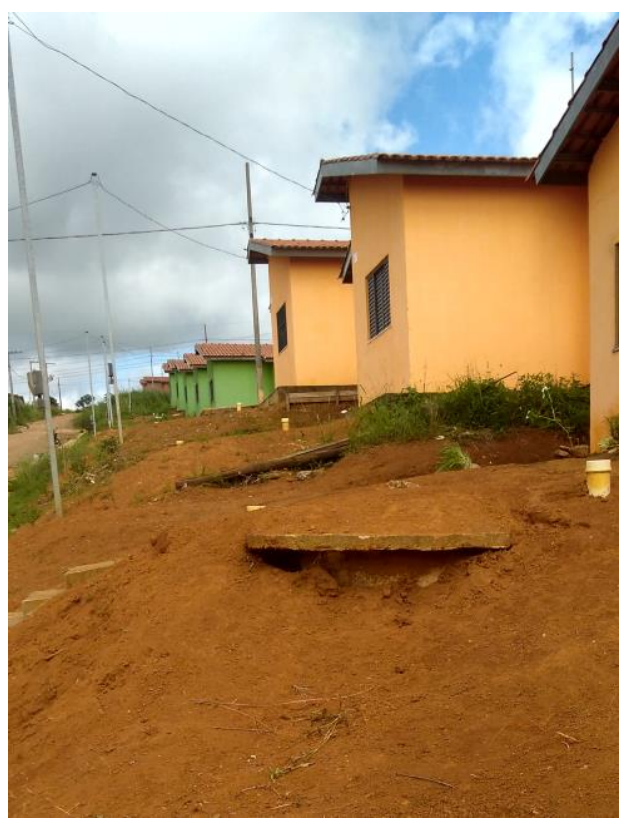

Figura 4: Solo cedendo - vista de várias resistências. Fonte: dos autores.

Como atesta a Figura 3, a fundação tipo radier passa a ter sua superfície de baixo (que deveria estar completamente em contato com o solo) exposta e por conta disto, a resistência de cálculo do solo - parâmetro básico para o dimensionamento estrutural da fundação - não é atingida, fato que pode desencadear várias outras manifestações patológicas nas edificações.

A Figura 4 mostra que o solo em deslizamento passa a deixar exposto parte do sistema sanitário de fossa, filtro e sumidouro das edificações, que, caso não seja resolvido, pode levar a futuros problemas com o sistema de esgoto do $\mathrm{CH}$.

A Figura 5 mostra um sistema de contenção lateral feito de tábuas de madeira, pelos próprios moradores da edificação, a fim de impedir o deslizamento do solo; como é notória a precariedade na figura, é necessário que seja imposta uma solução definitiva e duradoura a fim de resolver de modo integral o problema.

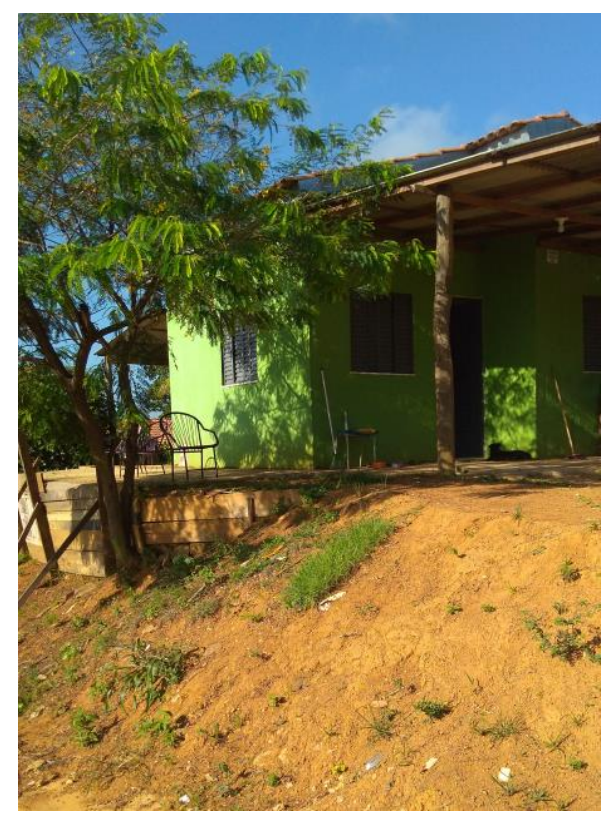

Figura 5: Sistema de contenção de madeira provisório improvisado pelos próprios moradores. Fonte: dos autores. 
A Figura 6 apresenta uma das situações mais drásticas encontradas: uma residência com desnível de ângulo quase reto. Dadas as condições de instabilidade do solo, faz-se urgente a tomada de medidas corretivas a fim de impedir um possível deslizamento de terra que pode pôr em risco a vida dos ocupantes da edificação e de sua edificação vizinha.

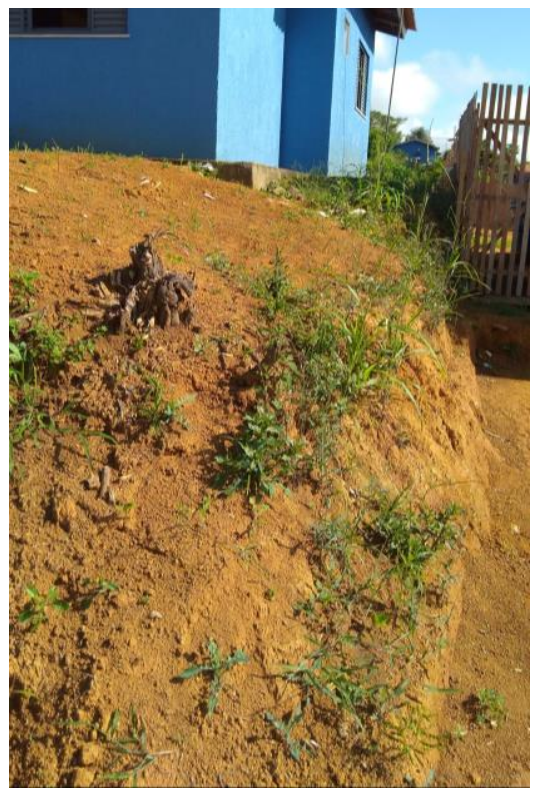

Figura 6: Caso de desnível de elevada inclinação. Fonte: dos autores.

As quatro Figuras anteriormente apresentadas edificações sem a cobertura vegetal. Esta foi prevista para ser colocada como a última etapa antes da finalização da obra, entretanto, por fatores financeiros, a empresa que operava esta obra precisou interromper suas atividades sem cumprir esta etapa. Este é um fator que justifica e potencializa o problema da instabilidade do solo encontrado no $\mathrm{CH}$.

\subsection{Solução de contenção para desníveis de até $1,5 \mathrm{~m}$ - talude com proteção vegetal e drenagem no pé do talude}

Conforme orientado pelo código de práticas da Caixa Econômica Federal, para desníveis de até 1,5m, foi proposta a solução de talude munido de proteção vegetal em toda sua extensão com dispositivos de drenagem no pé do talude (calha de concreto pré-moldada tipo meia cana de $200 \mathrm{~mm}$ de diâmetro). Optou-se o uso de calhas de concreto ao invés de calhas de PVC devido a maior resistência superficial do concreto quando sujeito às intempéries promovendo maior durabilidade a médio e longo prazo, justificando o investimento inicial. A Figura 7 mostra o projeto deste taludamento. Vale ressaltar que o passeio já faz parte do projeto inicial, não entrando na orçamentação da solução proposta.

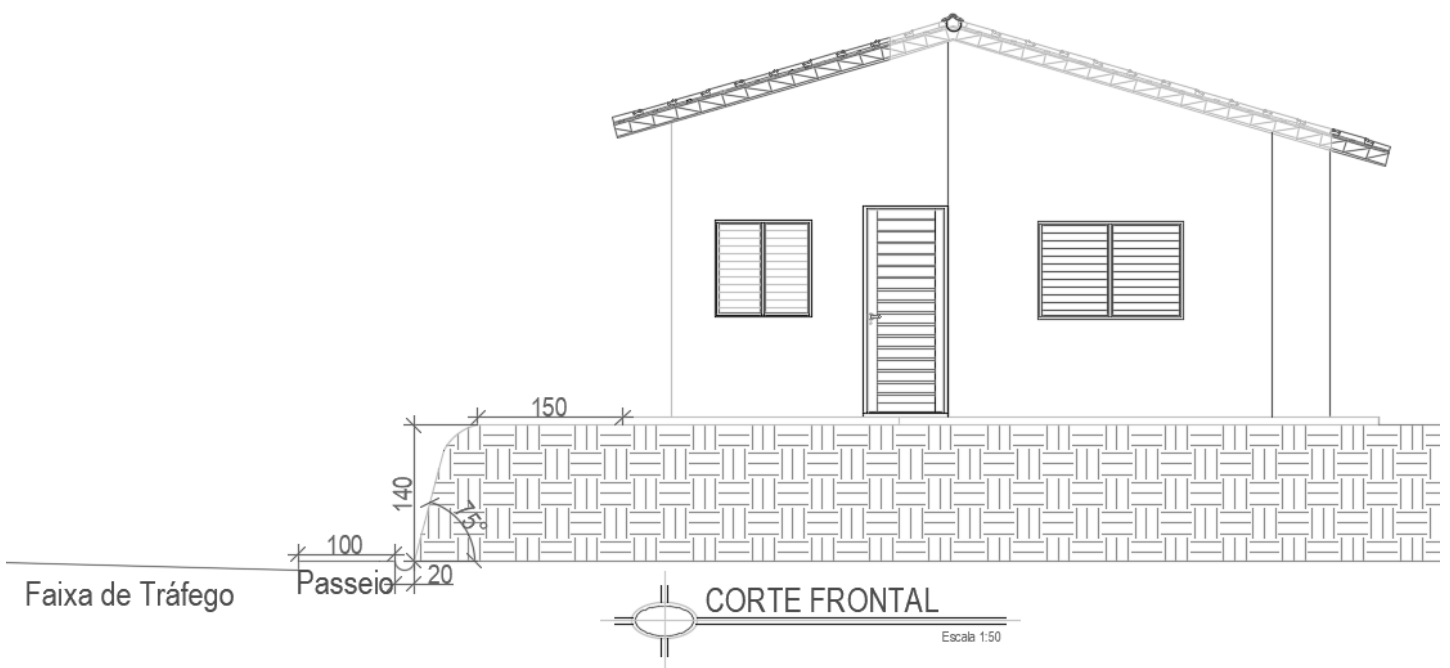

Figura 7: Taludamento e drenagem no pé do talude. Cotas em centímetros. Fonte: dos autores. 
A Figura 8 apresenta uma vista superior que considera a necessidade da solução tanto na frente quanto em um dos lados (neste caso, lado esquerdo), sendo válido destacar que houve casos em que a solução só se fez necessária na parte frontal da edificação.

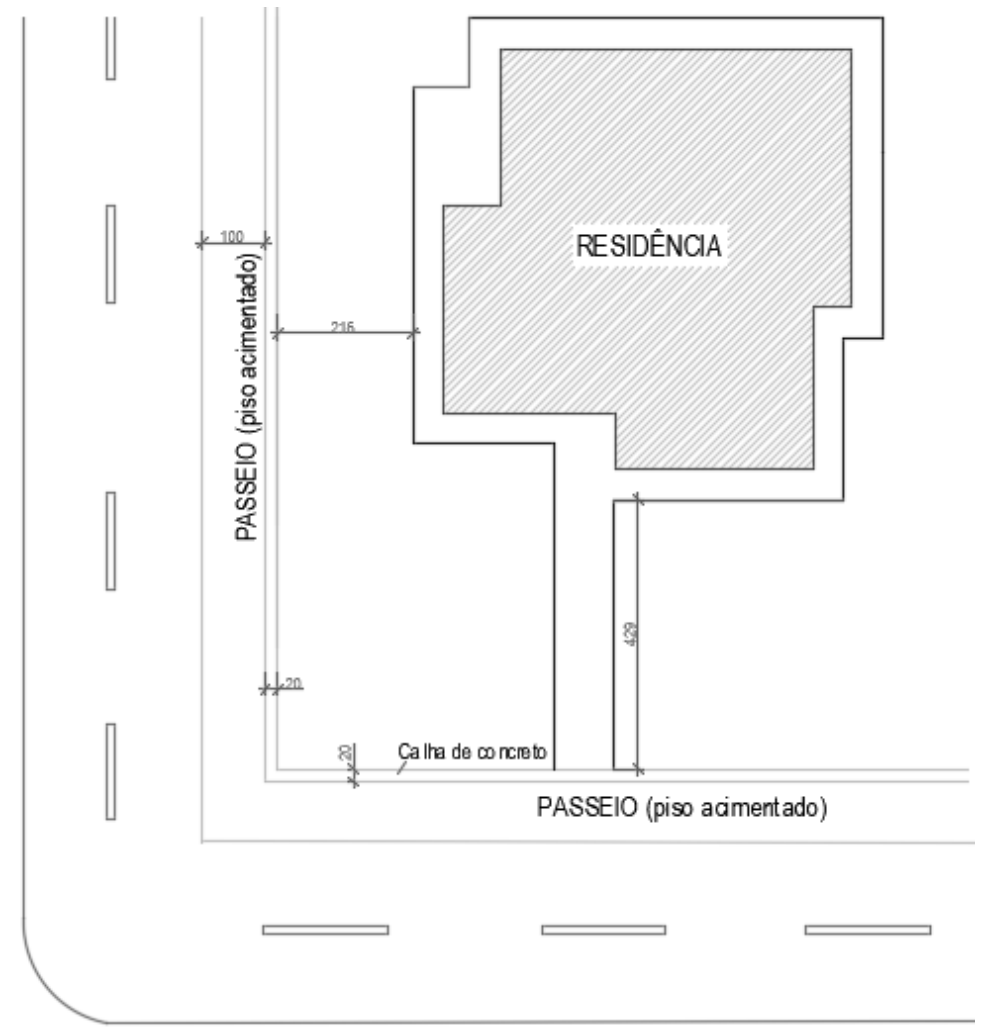

Figura 8: Vista superior. Cotas em centímetros. Fonte: dos autores.

A Tabela 1 apresenta a quantidade de casas que necessitam de taludamento em um e em dois lados:

Tabela 1 - Necessidade de talude

\begin{tabular}{lc}
\hline \multicolumn{2}{c}{ Necessidade de talude e dreno no pé do } \\
talude
\end{tabular}

Fonte: dos autores.

A Tabela 2 mostra o orçamento desta solução, que já inclui materiais, mão de obra e encargos sociais:

Tabela 2 - Orçamento

\begin{tabular}{ccccc}
\hline Serviço & Unidade & Quantidade & $\begin{array}{c}\text { Custo } \\
\text { Unitário } \\
(\mathbf{R} \$)\end{array}$ & $\begin{array}{c}\text { Custo } \\
\text { Total } \\
(\mathbf{R} \$)\end{array}$ \\
\hline Plantio de grama São Carlos em leivas & $\mathrm{m}^{2}$ & 7335,8 & 31,80 & $233.278,44$ \\
Calha em concreto simples, em meia cana, diâmetro $200 \mathrm{~mm}$ & $\mathrm{~m}$ & 2004,6 & 48,10 & $96.421,26$ \\
\hline
\end{tabular}

Fonte: dos autores.

Como notório através do orçamento exposto acima, o custo desta solução é de $\mathrm{R} \$ 329.699,70$, um valor bastante expressivo considerando o padrão popular do $\mathrm{CH}$. Nota-se em termos financeiros o impacto que estes serviços têm sobre o custo da obra. 


\section{CONCLUSÕES}

Muitos empreendimentos de grande porte, ao não considerar as especificidades do local, ignoram as orientações e a ausência de projetos traz consideráveis prejuízos e custos com obras de reformas e adequações que levariam a custos finais substancialmente menores, caso fossem projetados e executados adequadamente. No caso do estudo de caso em questão, como notório através dos orçamentos apresentados, o custo total com as soluções para 137 residências teve o valor de aproximadamente $330.000,00$ reais.

Deste modo, o projeto proposto por este estudo trouxe solução à problemática apresentada das manifestações patológicas ocorrentes nos solos em desnível das edificações do residencial Cristo Vive, através da elaboração de projeto adequado à realidade e topografia local além de estar em conformidade com o código de práticas da Caixa Econômica Federal.

\section{REFERÊNCIAS}

ALVES, L. G; THOMÉ, V. M; TOSTA, J. P. Manifestações patológicas em casas populares: uma análise de custo. Estudo \& debate. Lajeado. v. 24. n. 2. P. 268-294. 2017. Disponível em: < http://univates.br/revistas/index.php/estudoedebate/article/view/1345>. Acesso em: 05 nov. 2019.

ALONSO, Urbano Rodriguez. Previsão e controle das fundações. São Paulo: Edgar Blucher Ltda, 2011.

CAIXA ECONÔMICA FEDERAL. Programa de olho na qualidade. Código de práticas CAIXA. V006. 2016. Disponível em:<http://www.caixa.gov.br/voce/habitacao/minha-casa-minha-vida/de-olho-naqualidade/Paginas/default.aspx>. Acesso em: 10 nov. 2019.

CAIXA ECONÔMICA FEDERAL. SINAPI - Custo de composições analítico. Versão nov. 2019. Belém, Planilha em Microsoft Excel. Disponível em: <http://www.caixa.gov.br/site/Paginas/downloads.aspx\#categoria_651>. Acesso em: 10 dez. 2019.

FEITAS, M. S.; ALVES, E. C.; MARINHO, J. L. A. Estudo de manifestações patológicas pó-ocupação identificadas no conjunto habitacional do programa minha casa, minha vida a cidade de Juazeiro do Norte-CE. XIII Congresso Internacional sobre patologia e reabilitação de estruturas. Crato. Disponível em: < http://urca.br/itec/images/pdfs/artigo\%20cinpar.pdf>. Acesso em: 10 nov. 2019.

GERSCOVICH, Denise M. S. Estabilidade de Taludes. 2. ed. São Paulo: Oficina de textos, 2016.

GOMES, B. M. M.; FARO, A. A. dos S.; NASCIMENTO, T. M.; Inspeção da Qualidade de Habitações Populares Após Entrega. Revista de Engenharia e Pesquisa Aplicada, v. 2, n. 3, 28 ago. 2017. Disponível em: < http://revistas.poli.br/index.php/repa/article/view/693>. Acesso em: 10 nov. 2019.

LUIZ, Bruna Julianelli. Projeto Geotécnico de uma estrutura de contenção em concreto. 2014. Projeto de conclusão de curso (Bacharelado em Engenharia Civil) - Universidade Federal do Rio de Janeiro, Rio de Janeiro, 2014. Disponível em: < http://www.monografias.poli.ufrj.br/monografias/monopoli10011764.pdf >. Acesso em: 05 nov. 2019.

MICHEL, Gean Paulo. Modelagem de Estabilidade de Encostas com consideração do efeito da vegetação. 2013. Dissertação (Mestrado em engenharia ambiental) - Universidade Federal de Santa Catarina, Florianópolis, 2013. Disponível em: < https://repositorio.ufsc.br/handle/123456789/107096>. Acesso em: 08 nov. 2019.

MILITITSKY, Jarbas; CONSOLI, Nilo Cesar; SCHNAID, Fernando. Patologia das Fundações. São Paulo: Oficina de Textos, 2005.

PINOTTI, Alexandre Mathias; CARNEIRO, Celso Dal Ré. Geologia estrutural na previsão e contenção de queda de blocos em encostas: aplicação no Granito Santos, SP. Terrae Didática, Campinas, v. 09, p. 132-168, 2013. Disponível em: < https://periodicos.sbu.unicamp.br/ojs/index.php/td/article/view/8637402>. Acesso em: 05 nov. 2019.

SOARES, R da C.; CARVALHO R, K. P.; VALIN JR, M. de O.; ROCHA, A. F. da; Verificação de manifestações patológicas em condomínios residenciais do programa "Minha casa, Minha vida" ocasionados por falta de 


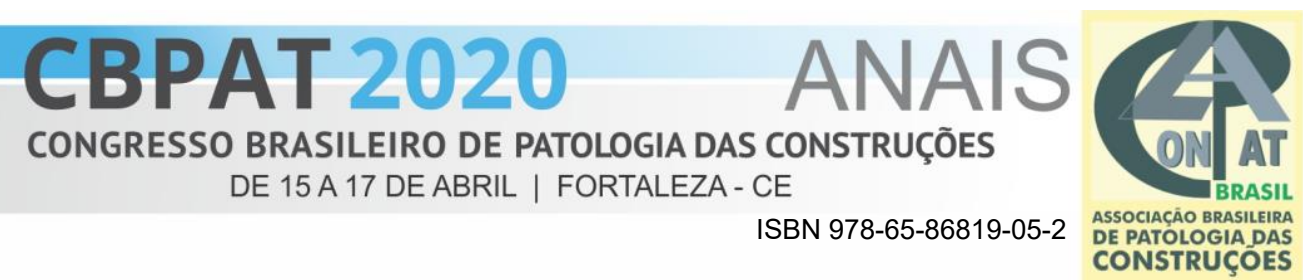

manutenção preventiva da baixada cuiabana. $1^{\circ}$ Congresso Brasileiro de Patologia das Construções. Alconpat Brasil. Disponível em: <

https://www.researchgate.net/publication/309899636_VERIFICACAO_DE_MANIFESTACOES_PATOLOGICAS_E M_CONDOMINIOS_RESIDENCIAIS_DO_PROGRAMA_MINHA_CASA_MINHA_VIDA_OCASIONADOS_POR _FALTA_DE_MANUTENCAO_PREVENTIVA_DA_BAIXADA_CUIABANA >. Acesso em: 10 nov. 2019. 